\title{
BIG DATA ON DIGITAL LOGISTICS IN SUPPLY CHAIN RISK PERSPECTIVE
}

\author{
Resista Vikaliana \\ Researchers at LPPM Institut Ilmu Sosial dan Manajemen Stiami \\ Email: resista@stiami.ac.id
}

\begin{tabular}{ll}
\hline ARTICLE INFO & ABSTRACT \\
\hline Keywords: & In Industry 4.0, digital transformation moves quickly, flexibly and efficiently. Logistics \\
& and supply chains have transformed into web-based. Internet of things (IoT) and Big \\
Big Data, & Data are important in the decision making process. The importance of big data doesn't \\
Logistics, & revolve around how much data you have, but what you do with it. In addition to the \\
Key Risk Indicators & opportunities to use big data, there are possible risks that must be anticipated. The wide \\
& range of data that can be obtained, so that in practice key risk indicators will act as an \\
& early warning system for the entity. Key risk indicators and their parameters.
\end{tabular}

\section{INTRODUCTION}

Big data is not all about having an unlimited amount of information, but rather about receiving quality information at certain times that are significant to a business. Big data can be defined as multimedia rich and interactive low-cost information resulting from mass communication. It offers customers a better understanding of new products and provides new, simplified modes of large-scale interaction between customers and firms (Zhan et al, 2016). In Industry 4.0, digital transformation moves quickly, flexibly and efficiently. Logistics and supply chains have transformed into web-based. Internet of things (IoT) and Big Data are important in the decision making process.

In the last few years in the digital era, data availability has doubled every year. In 2010 the data volume was 2,000 exabytes, while in 2015 it was 10,000 exabytes. Predicted data volume in 2020 is not less than 40,000 exabytes. In addition to large volumes of data, data characteristics are now substantially different from the characteristics of data in previous years.

Witkowski, 2017 do research that states 'smart' solutions which could be recognised as innovative solutions in both areas: technology and organisation. The above mentioned solutions could be implemented by logistics which, in the era of globalization, plays a very important role.

First, current data is increasingly flowing in large quantities from various equipment connected to the internet, such as smartphones, RFID, webcams, and sensor networks. This equipment produces data flow data continuously without human intervention. 
Second, current data is very varied and unstructured, ranging from pictures, sounds, blog entries, discussion forums, and e-commerce catalogs. All of this data is in large, fast, and varied volumes (3Vs: volume, velocity, and variety) which in its development is a characteristic of Big Data. The company currently manages and analyzes Big. Data to increase the value of information in business decision making.

In logistics industry, there are many challenges mainly with the integration of E-commerce and new sources of data such as smartphones, sensors, GPS and other devices. Those new data sources generate daily a huge quantity of unstructured data, to deal with such complex data, the use of big data analytic tools becomes an obligation, such as those through exploring technology-driven tracking strate-gies, financial performance relations with data driven supply chains, and implementation issues and supply chain capability maturity with big data (Kannan, 2018).

In this context, many works have been done recently in the integration of big data analytics in the logistics industry. ig data is revolutionizing many fields of business, and logistics analytics is one of them. The complex and dynamic nature of logistics, along with the reliance on many moving parts that can create bottlenecks at any point in the supply chain, make logistics a perfect use case for big data. For example, big data logistics can be used to optimize routing, to streamline factory functions, and to give transparency to the entire supply chain, for the benefit of both logistics and shipping companies alike. Third party logistics companies and shipping companies both agree.

Huge information isn't tied in with having a boundless measure of data, yet rather about accepting quality data at specific occasions that are critical to a business. Enormous information can be characterized as mixed media rich and intuitive ease data coming about because of mass correspondence. It offers clients a superior comprehension of new items and gives new, improved methods of substantial scale communication among clients and firms (Zhan et al, 2016). In Industry 4.0, advanced change moves rapidly, adaptably and effectively. Coordinations and supply chains have changed into electronic. Web of things (IoT) and Big Data are vital in the basic leadership process.

Over the most recent couple of years in the advanced time, information accessibility has multiplied each year. In 2010 the information volume was 2,000 exabytes, while in 2015 it was 10,000 exabytes. Anticipated information volume in 2020 isn't under 40,000 exabytes. Notwithstanding huge volumes of information, information qualities are presently considerably unique in relation to the attributes of information in earlier years. To begin with, current information is progressively streaming in substantial amounts from different hardware associated with the web, for example, cell phones, RFID, webcams, and sensor systems. This hardware produces information stream information consistently without human intercession. Second, current information is extremely differed and unstructured, running from pictures, sounds, blog sections, talk discussions, and internet business indexes. The majority of this information is in vast, quick, and differed volumes (3Vs: volume, speed, and assortment) which in its improvement is a normal for Big Data. The organization right now oversees and dissects Big. Information to expand the estimation of data in business basic leadership. 
The link between the results of big data analysis and decision making is certainly not an easy thing, management is needed that is not worried about change. The reason is, even if the data analysis section has worked well, but the input is not accepted and cannot be practiced, it is ultimately useless.In addition to the opportunities to use big big data, there are possible risks that must be anticipated. From this risk point another thing that is very important is how government regulations can minimize the potential dangers of big data. In Indonesia alone, the legal instruments to regulate big data still need to be formulated to avoid future fraud, privacy issues, including one of them. This study aims to find out the use of big data in logistics from a supply chain risk perspective.

\section{LITERATURE REVIEW}

\section{Big Data}

Big data is a term that describes the large volume of data - both structured and unstructured - that inundates a business on a day-to-day basis. But it's not the amount of data that's important. It's what organizations do with the data that matters. Big data can be analyzed for insights that lead to better decisions and strategic business moves. (www.sas.com. 2018). Based on state-of-the-art literature review, four themes for big data applications in retail logistics: availability, assortment, pricing, and layout planning (Aktas, et all 2017).

The significance of huge information doesn't rotate around how much information you have, yet what you do with it. You can take information from any source and break down it to discover answers that empower 1) cost decreases, 2) time decreases, 3) new item improvement and advanced contributions, and 4) shrewd basic leadership. When you join huge information with powerful investigation, you can achieve business-related assignments, for example,

- Determining underlying drivers of disappointments, issues and imperfections in close continuous.

- Generating coupons at the purpose of offer dependent on the client's purchasing propensities.

- Recalculating whole hazard portfolios in minutes.

- Detecting fake conduct before it influences your association

The idea of enormous information picked up force in the mid 2000s when industry expert Doug Laney explained the now-standard meaning of huge information as the three Vs:

1. Volume. Associations gather information from an assortment of sources, including business exchanges, internet based life and data from sensor or machine-to-machine information. Before, putting away it would've been an issue - however new advancements, (for example, Hadoop) have facilitated the weight.

2. Velocity. Information streams in at an extraordinary speed and should be managed in an auspicious way. RFID labels, sensors and keen metering are driving the need to manage deluges of information in close constant. 
3. Variety. Information comes in a wide range of organizations - from organized, numeric information in customary databases to unstructured content reports, email, video, sound, stock ticker information and budgetary exchanges.

As per SAS, there are two extra measurements with regards to enormous information:

1. Variability. Notwithstanding the expanding speeds and assortments of information, information streams can be exceptionally conflicting with occasional pinnacles. Is something drifting in online life? Day by day, regular and occasion activated pinnacle information burdens can be trying to oversee. Considerably more so with unstructured information.

2. Complexity. The present information originates from various sources, which makes it hard to connect, coordinate, purge and change information crosswise over frameworks. Be that as it may, it's important to associate and correspond connections, chains of command and numerous information linkages or your information can rapidly winding wild.

Big Data in Logistics goes path past the trendy expressions and offers certifiable utilize cases. It uncovers what's occurring now with Big Data, and what's probably going to occur later on. It shows an energizing and critical job for complex information investigation - the job of merging the generally divided coordinations industry. Fruitful coordinations suppliers are probably going to seize shaft position as "web search tools in the physical world".

This most recent pattern report proposes and investigates three distinct classifications of data abuse:

- Operational effectiveness: constant course improvement, swarm based pickup and conveyance, vital system arranging, and operational scope quantification

- Customer encounter: client devotion administration, constant administration change and item development, and hazard assessment and versatility arranging

- New plans of action: showcase insight for little and medium-sized undertakings, budgetary interest and inventory network investigation, address confirmation, and ecological knowledge

\section{Risk}

The company's activities cannot be separated from risk management activities. Risk can be defined as the outcome volatility which is generally in the form of the value of an asset or debt. Companies in their activities face two types of risk, namely business risk and non-business risk. Business risk is all risks related to the company's business to create competitive advantages and provide value to shareholders. Business risks relate to products such as technological innovation, product design, and product marketing. Operating leverage related to the level of fixed costs and variable costs is also part of business risk. This business risk for the company is a risk that can be controlled.

While other risks that cannot be controlled by the company are categorized as non-business risks and one of them is strategic risk as a result of fundamental changes in the economic and political environment. Where did the risk come from? Risks can arise from various sources. Risks created by humans such as business cycles, inflation, changes in government policies and war. Risks can also arise from invisible 
natural phenomena such as weather and earthquakes. Risks can also arise from long-term economic growth, technological innovations that can lead to current technology being used and creating unemployment. Therefore the risks and willingness to accept risk are important results for economic growth.

There are people who try to avoid risk, but there are also people who are otherwise very happy to face risk while others may not be affected by the risk. Understanding people's attitudes towards this risk can help to understand how important risks are to be handled properly.

Risk is believed to be unavoidable. With regard to the public sector that demands transparency and improved performance with limited funds, the risks faced by Government agencies will increase and increase. Therefore, understanding risk is a necessity to be able to determine the priorities of strategies and programs in achieving organizational goals.

Risk can be reduced and even eliminated through risk management. The role of risk management is expected to anticipate the environment to change quickly, develop corporate governance, optimize the preparation of strategic management, secure the resources and assets of the organization, and reduce reactive decision making from top management.

Risk management is a structured approach / methodology for managing uncertainty related to threats; a series of human activities including: Risk assessment, developing strategies to manage it and risk mitigation using resource empowerment / management. Strategies that can be taken include moving risk to other parties, avoiding risks, reducing the negative effects of risk, and accommodating some or all of the consequences of certain risks.

Traditional risk management focuses on risks arising from physical or legal causes (such as natural disasters or fire, death, and lawsuits. Financial risk management, on the other hand, focuses on risks that can be managed using financial instruments. from the implementation of risk management is to reduce the different risks associated with the chosen field at a level that is acceptable to the community, this can be in the form of various types of threats caused by the environment, technology, people, organizations and politics. the implementation of risk management involves all means available to humans, in particular, to risk management entities (human, staff and organization).

Another understanding of risk management is a series of steps that help a software to understand and regulate uncertainty (Roger S. Pressman). When we are working on software development, we often face a variety of uncomfortable situations such as development delays or development costs that exceed the budget. This is because we are not ready to face various possible risks that will occur. For this reason, it is necessary to identify the actions that must be taken to prevent or minimize these risks.

\section{$\underline{\text { Speculative Risk and Pure Risk }}$}

Risks can be categorized into two forms:

1. speculative risk, and

2. pure risk. 
Speculative risk

Speculative risk is a situation faced by a company that can provide benefits and can also provide losses. Speculative risk is sometimes also known as business risk. Someone who invests funds in a place facing two possibilities. The first possibility is that the investment is profitable or even the investment is detrimental. Risks faced like this are speculative risks. Speculative risk is a situation faced that can provide benefits and can also cause losses

\section{Pure risk}

Pure risk (pure risk) is something that can only cause harm or nothing happens and may not be profitable. One example is a fire, if the company gets a fire, the company will suffer a loss. Another possibility is that there is no fire. Thus, fires only cause losses, not cause profits, unless there is intent to burn with certain intentions. Pure risk is something that can only cause harm or nothing and cannot be profitable. One way to avoid pure risk is with insurance. Thus the amount of loss can be minimized. That's why pure risk is sometimes known as insurable risk.

The main difference between speculative risk and pure risk is the possibility of profit or not, for speculative risk there is still a possibility of profit while for pure risk there is no possibility of profit.

\section{$\underline{\text { Risk and Risk Management }}$}

Risk Management is a culture, process and structure that is directed at realizing potential opportunities and at the same time managing adverse impacts (Australian Risk Management Standard, 2004). In other words, formal systematic handling methods are concentrated on identifying and controlling events or events that have the possibility of change. unwanted

\section{$\underline{\text { Risk Management Stages }}$}

In general, the supply chain risk management process consists of risk identification, risk analysis, risk evaluation and risk mitigation. Risk identification is suggested as a fundamental step in the risk management process. Most potential risks, not only within the organization, but also between members of the supply network and between supply networks and the environment must be identified. Unidentified risks can cause misdirected directions in the supply chain management process such as creating a risk mitigation plan. This can lead to inaccurate or inappropriate strategies to control risks and can incur large costs.

The principles of risk identification are a process carried out by the company systematically and continuously in identifying property, liabilities and exposures personnel. The following are methods of identifying risks:

Financial Reports, Risk Analysis Questionnaire, Flow Chart of Goods, Interaction Methods (observation, interviews, document studies), Direct Inspection, External Interactions, Environmental Analysis, Brainstorming, Personal Experience and Intuition. 


\section{Supply Chain Risk Framework}

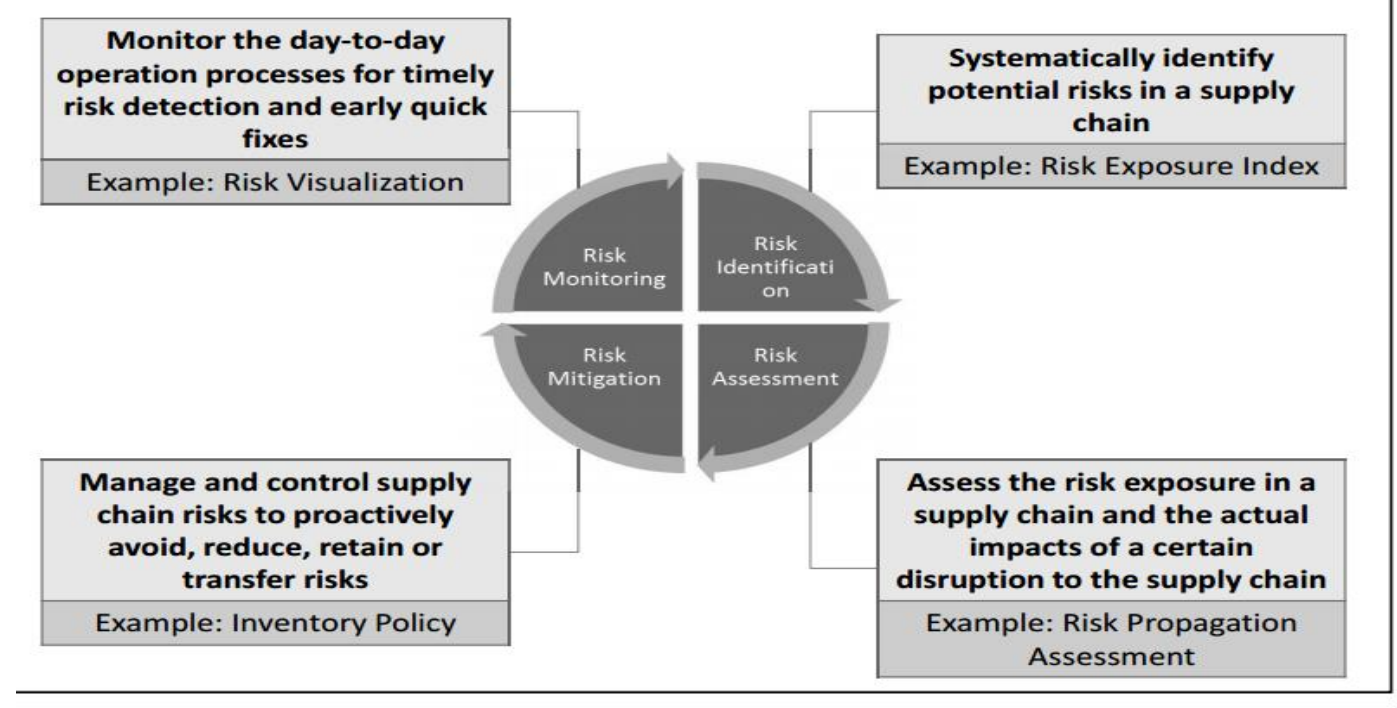

III. METHOD

This research is a library research. This research activity includes data collection through literature. Data collection, at this stage conducted keyword searches related to city logistics and the location of scientific articles from journals, proceedings, and text book.

\section{RESULT AND DISCUSSION}

New trends and strategies across enterprise logistics operations, combined with a new generation of logistics technology, will dramatically change the way leading companies pursue supply chain management.

Today, logistics professionals have a powerful array of new digital logistics weapons that can be strategically deployed to unlock significant value and create customer-focused logistics systems that build long-term competitive advantage.

Those companies that recognize this changing landscape and invest prudently in process change and supporting digital logistics technologies will reap vast benefits. Those that hesitate may find themselves in the next 2-3 years at a competitive disadvantage that is too great too overcome.

The logistics industry belongs to an industry that is full of risks. Risks in the logistics industry come in various forms. From small to large scale, to unpredictable natural disasters that can disrupt logistics operations from day to day.

It is very difficult to have the right planning at every risk that occurs, where it is disturbing. But we can take anticipatory steps by implementing risk management, so that when risks occur we have prepared everything.

Preparatory steps that must be taken start from how to recognize the forms of risk, assess the scale of risk, then how to overcome these risks. 


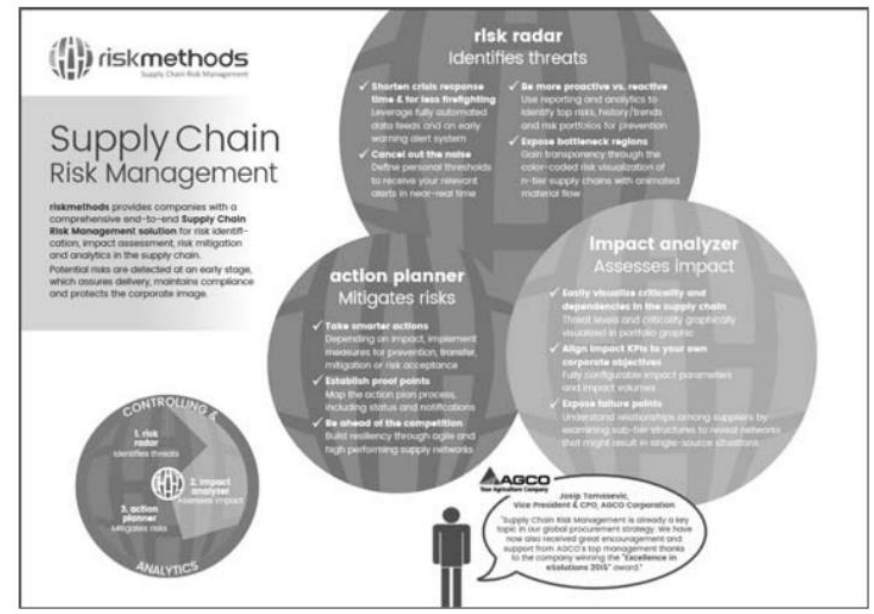

The type of risk that can occur can be classified based on how to control the risk, among others

\section{Risk that can be anticipated}

Risks that occur can be controlled, calculated and anticipated. Included in this are the risks caused by the business being carried out. For example: - Competition with competitors - Employee skills - Changes in the IT system - Security violations - Supplier quality - Employment issues - Regulation - Rapid growth

2. Risks that can be anticipated but cannot be controlled For example: - Fluctuations from demandDisruption of supply- Delay transport- BBM prices- Prices of raw materials- Limitations of planning

3. Risks that cannot be anticipated This type of risk cannot be controlled and is difficult to anticipate. Examples of this type of risk include: - Natural disasters - Changes in social and political conditions War - Outbreaks of diseases - Acts of terrorism - Accidents

From the risks that occur, the process at the time of risk occurs, planning and use of tools and technology can improve the ability to handle risk, reduce handling time and minimize the impact.

Risks arising from the design of business processes

The design of business processes does not escape the causes / potential factors of risk. Some examples, for example: - Lean and Just in Time (JIT) implementation in the Lean and Just in Time concepts can pose a risk to the time to do a shorter reaction, besides that there is less availability of stocks. Outsoutcing By using outsourcing solutions, then the lead time will be longer, other than that there will also be a loss of control over the work done- The policy of using one supplier Will be a risk when the supplier is unable to meet the demand.

Impact of risk occurrence Some of the effects caused by the occurrence of risk associated with earnings include: - Operational income - Return on sales-return on assets- sales growth- Growth costsGrowth of inventory.

Challenges for risk management - Increasing and changing forms of risk - Risk management varies across industries. There is never the same solution. - Efficiency versus risk.

Advantages of implementing risk management - Can prevent the occurrence of a disaster, prevent one risk can prevent other risks that might have a greater impact - Maximize reaction time when there is a 
risk - Able to give the right decisions - More ready to face risk - Minimize damage caused - Customers satisfied.

As a logistician, we cannot predict what will happen in the future, nor can we plan the risks of what happens in your logistics company. But you can take a proactive approach to risk management.

Risk Identification Method

1. Financial Report

2. Risk Analysis Questionnaire

3. Chart flow Item flow

4. Interaction Methods (observation, interviews, document study)

5. Direct Inspection

6. External interactions

7. Environmental Analysis

8. Brainstorming

9. Personal Experience and Intuition

Stages of Key Risk Indicators

1. Target Setting

2. Test Target

3. Making Risk Identification (Key Risk Indicator)

4. Determination of Result Criteria, Possible Criteria, and Risk Map

\section{DISCUSSION}

Uncertainty in carrying out activities both from internal and external entities can affect the achievement of the stated goals. Uncertainty acts as a source of the emergence of things or risks that can threaten or disrupt the operational activities of the entity or that can lead to the inability of the entity to realize the opportunities that exist to assist the entity in achieving its objectives. The demand to manage these things or risks has become a particular priority for the entity as a form of efforts to maintain and ensure the sustainability of the entity itself.

Risk management is a management system that can be applied to manage the risks faced by an entity. In its application, various tools can be used by entities to realize effective risk management implementation. One of them is a key risk indicator, which is one of the tools to assist in risk monitoring activities.

Key risk indicators are certain events or things that give an indication of a risk event. The use of key risk indicators in risk monitoring activities can provide an early warning or information to the entity's management that the likelihood of a risk event is increasing. This can be realized because monitoring is carried out to focus on events that are indicative of a risk event occurring, not the risk event itself. Based on this warning or information, the entity can carry out various mitigation actions early in order to reduce the 
likelihood of the occurrence of risk events and the possible impacts of the risk (if they occur). So that in practice key risk indicators will act as an early warning system for entities.

In practice, in order to be a measurable indicator that is easy to monitor and can act as an early warning system, key risk indicators are determined along with the parameters, which consist of:

1. Medium Threshold,

An initial threshold that gives an indication of a risk event can occur with a small possibility.

2. The High Threshold, is the maximum threshold that gives an indication

a risk event can occur with a high probability.

3. Unit of measure (Value Unit)

Threshold unit.

\section{CONCLUSION}

The use of big data in logistics from a supply chain risk perspective can not be separated from various risks. So wide is the data that can be obtained, so that in practice key risk indicators will act as an early warning system for the entity. Key risk indicators and their parameters is one way to minimize risk

\section{REFERENCES}

Govindan, Kannan ${ }^{\mathrm{a}}$, T.C.E. Cheng ${ }^{\mathrm{b}}$, Nishikant Mishra ${ }^{\mathrm{c}}$, Nagesh Shukla. 2018. Big data analytics and application for logistics and supply chain management. www.elsevier.com/locate/trewww.elsevier.com/locate/tre (http://dx.doi.org/10.1016/j.tre.2018.03.)

Witkowski. Krzysztof Witkowski 2017. Internet of Things, Big Data, Industry 4.0 Innovative Solutions in Logistics and Supply Chains Management. Peerhttp://creativecommonsreviewunderresponsibility.org/licenses/byof-thenc-nd/4organizing.

https://www.researchgate.net/publication/280934975_Big_Data_Analytics_for_Logistics_and_Transportatio $\underline{\mathrm{n}}$ [accessed May 6 2018].

$\underline{\text { www.datapine }}$

https://www.supplychainmarket.com/doc/the-new-era-of-digital-logistics-0001 http://www.arthanugraha.com/2015/01/13/manajemen-risiko-logistik/ http://mediaindonesia.com/read/detail/7414-menyambut-big-data-peluang-dan-tantangannya 